

\title{
Incorporating Carbon Penalties into Supplier Selection in the Supply Chain
}

\author{
Kanika Gandhi ${ }^{1}$; Diego Galar ${ }^{2}$; P. C. Jha ${ }^{3}$ \\ 1'gandhi.kanika@gmail.com; ${ }^{2}$ diego.galar@1tu.se; ${ }^{3}$ pcjha@yahoo.com \\ ${ }^{1,3}$ Department of Operational Research, University of Delhi \\ Delhi, India \\ ${ }^{2}$ Division of Operation and Maintenance Engineering, Lulea University of Technology, \\ Lulea, Sweden
}

\begin{abstract}
Supply chain management (SCM) practices have flourished since the 1990s. Enterprises realize that a large amount of direct and indirect cost can be managed from effective and efficient SCM practices. Supplier selection has great impact on integration of the supply chain relationship. Effective and accurate supplier selection decisions are significant components for procurement and distribution management in many firms to enhance their organizational performance. In this study a multiple sourcing procurement distribution optimization problem is considered. Three objective functions are minimization of costs, maximization of performance and minimization of carbon emission penalty cost respectively. In order to solve the problem, a fuzzy mathematical model and a fuzzy goal programming solution approach are proposed to satisfy the decision maker's aspirations for fuzzy goals. A real life case study is given to illustrate how the model is utilized.
\end{abstract}

Keywords-Carbon emission, Supplier selection, Carbon penalities, Supply cahin, Fuzzy goal programming, Deteriorating.

\section{INTRODUCTION}

In the current competition companies increasingly use their supply chain to compete and gain market share. Technology and process upgrades at companies clearly show that supply chain excellence is more widely accepted as an element of overall business strategy and that increasing value to customers is not just management's, but everyone's business. Today companies have understood that to make an important merger work, they would have to integrate its supply chain with their partners. In fact, the significant savings promised by the merger would not be possible without integrating activities in supply chain through all partners. The activities integrate in supply chain are procurement, manufacturing, inventory, distribution, logistics, retail store and end customer. Successful supply chain management, then, coordinates all these activities into a seamless process. It embraces and links all of the partners in the chain. To improve supply chain competitiveness, the companies must find and evaluate more efficient suppliers. Traditionally, supplier selection and evaluation methods focus on the requirements of single enterprises, and fail to consider the entire supply chain. Consequently, individual enterprises focus on developing their core capabilities and outsource non-core affairs to other partners or suppliers with different professional capabilities to upgrade their competitive advantage by applying these external and special sources and technology knowledge. In any supplier selection process, generally six main decision processes takes place viz: (1) make or buy, (2) supplier selection, (3) contract negotiation, (4) design collaboration, (5) procurement, and (6) sourcing analysis. Of these six decision process, supplier selection is one of the most vital and crucial decision and becomes more important when an organization has to select the supplier for more than one period and when the supplier's capacity, their quality level, lead time, and various cost parameters also vary. Therefore, the supplier selection for multi-period, multi-parts, and multi-source is a widely occurring phenomena in a large business organization while keeping the desired quality level. Hence, supplier selection is a multi-criteria problem which includes both tangible and intangible criteria, some of which may conflict.

On the other hand, finding coordination in procurement and distribution can be achieved by integrating means of coordination mechanisms as procurement, inventory, distribution, logistics and retail store in the optimization of the supply chain network. In a supply chain, if there is a single decision maker who tries to optimize the overall system, the structure is referred to as centralized. However, generally the various entities may have objectives' conflicts even when they belong to the same unit. For instance, procurement from supplier would be preferred in large lot sizes in order to reduce purchase costs. This would increase inventory amounts, and hence holding costs, which contradicts the objectives of the warehouses. On the other hand, a supply chain in which each entity tries to optimize its own system is referred to as decentralized. A centralized system leads to global optimization, whereas a decentralized system results in local optimization. Therefore, to achieve the global optimal solution in a decentralized supply chain, the conflicting objectives of the entities should be aligned through coordination issues. In the coordination, transportation of goods from one entity to another and inventory level at all the stages help in smooth integration. Proper inventory management has great influence on cost down and procurement stability for companies. In real world, the inventory of many products may face limitations as deterioration, deadlines of consumption (DOC), and vaporizing. That can be called as deteriorating inventory. 
When developing inventory model which have the traits of deterioration, it is very important to understand the traits and categories of deterioration by [1]. The deteriorating inventory has to be taken very seriously during coordination and may also be taken care with the help of return channels. This coordination can be adjoining in the above integration, as the transportation cost shall be associated in the return process. Finding out an optimum integration is important for understanding supply chain and its corresponding strategies and decisions as its members should be part of progression, which will be investigated in this paper.

\section{LITERATURE REVIEW}

In recent years, the studies of supply chain management focus on how to design the coordination schemes. Most work on coordinated supply chain scheduling focuses on coordinating the flows of supply and demand over a supply chain network to minimize the inventory, transportation and shortage costs. [2], [3] and [4] studied simplified models for integrated scheduling of production and distribution operations. The authors have analyzed computational complexity of various cases of the problem and have developed heuristics for NP-hard cases. [5] considered the problem of operations scheduling for capacitated multiechelon shipping network with delivery deadlines, where semi-finished goods are shipped from suppliers to customers through processing centers, with the objective of minimizing the shipping and penalty cost. The three polynomial-time solvable cases of this problem were reported: with identical order quantities; with designated suppliers; and with divisible customer order sizes. [6] developed a multi-objective mixed integer programming approach to address production, distribution and capacity planning of global supply chains considering cost, responsiveness and customer service level simultaneously.

A key component in developing a reliable supply chain is the selection of suppliers. Essentially, two types of supplier selection are prominent. In the first type (single sourcing), one supplier can satisfy the entire buyer's needs and the buyer needs to make only one decision: which supplier is the best. In the second and more common type (multiple sourcing), more than one supplier must be selected because no single supplier can satisfy all the buyer's orders. Hence, companies need to select both the best suppliers and how much quantity should be allocated among them for creating a constant environment of competitiveness [7]. Accordingly, multiple sourcing provides significant assurance of timely delivery and order flexibility due to the diversity of the firm's total orders [8]. Supplier selection is a multi criteria decision making (MCDM) problem containing both quantitative and qualitative criteria which, together, are in conflict. Goal programming (GP) is used widely for solving MCDM and multi-objective decision making (MODM) problems because of its simplicity and flexibility. Goal programming can handle relatively large numbers of decision variables, resource constraints, and objectives [9]. [10] proposed a multi-objective model for supplier quota allocation problem while demand was dependent on the offered price by suppliers. They solved their models using genetic algorithm and simulated annealing. [11] tried to construct a lot-sizing model with multi-suppliers and quantity discounts to minimize total cost over the planning horizon as a single-objective problem. The objective was to minimize total costs, where the costs include ordering cost, holding cost, purchase cost, and transportation cost.

[12] proposed a fuzzy multi-objective linear model for supplier selection in a supply chain by using an asymmetric fuzzy decision making technique to provide the decision maker to allocate different weights to various criteria. Bevilacqua et al. [13][5]* developed a fuzzy quality function deployment (QFD) approach for supplier selection problem. The quantitative techniques for supplier evaluation and selection can be categorized into three classes [14]: (1) multi-attribute decision making includes the linear weighting method and the analytical hierarchy process (AHP), (2) mathematical programming models include the linear programming models, mixed integer programming, multi-objective programming and data envelopment analysis, (3) intelligent approaches as for the last class include neural network based methods, expert systems, fuzzy decision making, hybrid approaches such as integrated AHP and linear programming, combined AHP, data envelopment analysis (DEA) and neural network has been applied for the supplier selection. Objective functions considered in the literature are minimizing the negative effect of vendor service rating, minimizing the negative effect of the economic environment [15], maximizing service and minimization of risk [16]. Objectives' aspiration levels are determined often by using ideal solutions. Other fuzzy parameters are buyer demand, vendors' quotas, and budget amount allocated to vendors, maximum capacity of vendors as right hand side constants. The parameters like consumption and performance parameters make the current study fuzzy. The paper shows a fuzzy multi-objective optimization model, conversion process of model in crisp process and the solution of the case discussed.

\section{PROBLEM DESCRIPTION}

The supply chain considered in this paper has three stages consisting of multiple independent suppliers with limited capacities, one intermediate point (warehouse), and one buyer (Retail store) along with return channel of deteriorated inventory. The model is a multi objective fuzzy optimization problem. The first objective of the model finds the optimum cost while ordering quantity from suppliers and procured at one warehouse. Further the inventory at warehouse is shipped to buyer as per requirement which incurs transportation cost and return channel cost of deteriorated inventory from retail store to warehouse. The transportation cost from supplier to warehouse is not discussed in the model as it is part of purchasing cost and supplier is taking care of it fully. The cost of transportation from warehouse to retail store uses transportation policies, who specify to take truckload (TL) policy, or truckload \& less than truckload (TL \& LTL) policy. The second objective chooses the best supplier on the bases of lot size 
acceptance and on-time delivery percentage. Third objective of the model find least carbon emission cost as per the distance travelled from supplier to warehouse, which is also one of the criteria to select a supplier.

Hence, the model discussed above integrates inventory, procurement and transportation mechanism to minimize all costs discussed above and also chooses the best supplier. The total cost of the model becomes fuzzy due to fuzzy holding cost and consumption. On the other hand, performance level is also fuzzy as percentage of on-time delivery and acceptances are fuzzy. So the model discussed above is fuzzy multi objective mixed integer non-linear model. In the solution process, the fuzzy model is converted into crisp and further fuzzy goal programming approach is employed where each objective could be assigned a different weight.

\section{MODEL FORMULATION}

The paper discussed a multi objective fuzzy optimization model, where first objective finds the optimum quantity; second objective find the best supplier and third objectives check carbon emission cost. The assumptions of the model says that demand at retail store is uncertain, supply of required quantity is instantaneous, available inventory at warehouse and retail store is positive at beginning of the planning horizon, which helps in managing ordered quantity from retail store and procurement from suppliers.

\section{A. Sets}

Product set with cardinality $P$ and indexed by $i$; Period set with cardinality $T$ and indexed by $t$; Supplier set with cardinality $J$ and indexed by $j$; Price break for carbon emission cost with cardinality $L$ and indexed by $l$.

\section{B. Parameters}

$C$ is fuzzy total cost; $C_{0} \& C_{0}^{*}$ are aspiration and tolerance

level of fuzzy cost respectively; $\tilde{P R}$ is total fuzzy the fuzzy performance of supplier; $P R_{0} \& P R_{0}^{*}$ are aspiration and tolerance level for fuzzy supplier's performance; $P C$ is cost of carbon emission; $\tilde{H S}_{i t} \& \overline{H S}_{i t}$ are fuzzy and defuzzified holding cost at warehouse; $\phi_{i j t}$ is unit purchase cost for $i^{\text {th }}$ product in $t^{\text {th }}$ period from $j^{\text {th }}$ supplier; $s$ is cost per weight of transportation in LTL policy; $\beta_{t}$ is fixed freight cost for each

truck load in period t; $\tilde{H D}_{i t} \& \overline{H D}_{i t}$ are fuzzy and defuzzified holding cost at retail store; $\lambda_{i t}$ is per unit inspection cost at retail store; $V h_{i t}$ is transportation cost of return channel from retail store to warehouse; $D C_{i t}$ is disposal cost of deteriorated quantity; $\widetilde{C R}_{i t} \& \overline{C R}_{i t}$ are fuzzy and defuzzified consumption at retail store respectively; $I S N_{i t} \& I D N_{i t}$ are inventory level at beginning of the planning horizon at warehouse and retail store; $\eta$ is constant deteriorating percentage at retail store; $w_{i}$ is per unit weight; $\omega$ is weight per full truck;
$\widetilde{D T}_{i j t} \& \overline{D T}_{i j t}$ are fuzzy and defuzzified on-time delivery percentage; $\tilde{A C}_{i j t} \& \overline{A C}_{i j t}$ fuzzy and defuzzified acceptance percentage; $C P_{i j}$ is the supplier's capacity; Dis ${ }_{j}$ is travelling distance from supplier $\mathrm{j}$ to warehouse; Amount $_{j t}$ is carbon emission threshold beyond which the higher emission cost incurs; Cost $P_{j t l}$ is cost of carbon emission; $D C_{a p}$ is disposal capacity at warehouse

\section{Decision Variables}

$I S_{i t} \& I D_{i t}$ are inventory levels at warehouse and retail house; $X_{i j t}$ is optimum ordered quantity of product i ordered in period $\mathrm{t}$ from supplier $\mathrm{j} ; X_{i t}$ is optimum ordered quantity of product $\mathrm{i}$ ordered in period $\mathrm{t}$ from all the suppliers; $L_{t}$ is total weighted quantity transported in stage I \& II respectively in period $t$ to retail store; $J_{t}$ is total number of truck loads in period $t ; y_{t}$ is weighted quantity in excess of truckload capacity; $u_{t}$ is usage of modes, either TL \& LTL mode (value is 1) or only TL mode (value is 0 ); $V_{i j t}$ is defined as, if ordered quantity is transported by supplier $j$ for product $i$ in period $t$ then the variable takes value 1 otherwise $0 ; D_{i t}$ is demand for product $i$ in period $t$ from retail store; $\mathrm{CO}_{i j t}$ is per unit carbon emission from supplier $\mathrm{j}$ to warehouse in period t; $P C_{j t l}$ is $l^{\text {th }}$ level of carbon emission cost activates as per the carbon emission threshold from supplier $j$ in period $t ; E X_{i t}$ is deteriorated inventory at retail store in period $t$ for product $i$.

\section{Formulation of Objective}

Fuzzy optimization is a flexible approach that permits adequate solutions of real problems when vague information is available, providing well defined mechanisms to quantify uncertainties directly. Therefore, we formulate fuzzy optimization model for vague aspiration levels on total cost, consumption, on-time delivery percentage and acceptance percentage where the decision maker may decide his aspiration levels on the basis of past experience and knowledge possessed by him.

Initially a bi-objective fuzzy model is formulated which discusses about fuzzy total cost and performance of the suppliers. The first objective of the model minimizes the total cost, including purchasing cost of goods from supplier, transportation cost from active supplier to warehouse, holding cost at warehouse for ordered quantity, transportation cost from warehouse to destination, cost of holding at retail store, inspection cost of the reached quantity at retail store, transportation cost of deteriorated quantity from retail store to warehouse and finally, disposal cost at warehouse.

$$
\begin{aligned}
& \operatorname{Min} \tilde{C}=\sum_{t=1}^{T} \sum_{j=1}^{J} \sum_{i=1}^{P} \phi_{i j t} X_{i j t} V_{i j t}+\sum_{t=1}^{T} \sum_{i=1}^{P} \tilde{H} S_{i t} X_{i t}+\sum_{t=1}^{T}\left[\left(s y_{t}+j_{t} \beta_{t}\right) u_{t}+\left(j_{t}+1\right) \beta_{t}\left(1-u_{t}\right)\right] \\
& +\sum_{t=1}^{T} \tilde{H} D_{i t} I D_{i t}+\sum_{i=1}^{P} \sum_{t=1}^{T} \lambda_{i t} X_{i t}+\sum_{t=1}^{T} \sum_{i=1}^{P} E X_{i t} V h_{i t}+\sum_{t=1}^{T} \sum_{i=1}^{P} E X_{i t} D C_{i t}
\end{aligned}
$$


The second objective discusses the performance of suppliers and maximizes the performance percentage of supplier as per delivery time percentage and acceptance percentage of ordered lot.

$$
\operatorname{Max} \tilde{P R}=\sum_{i=1}^{T} \sum_{j=1}^{J} \sum_{i=1}^{P}\left(\tilde{D} T_{i j t}+\tilde{A C}_{i j t}\right) V_{i j t}
$$

The third objective calculates carbon emission cost from active supplier to warehouse on the bases of carbon emission threshold. Carbon emission is calculated as per distance travelled.

$$
\operatorname{Min} P C=\sum_{t=1}^{T} \sum_{j=1}^{J} \sum_{i=1}^{P}\left(C o_{i j t} V_{i j t}\right) \sum_{l=1}^{L} \operatorname{Cos} t P_{j t l} P C_{j t l}
$$

\section{E. Constraints' Formulation}

The constraints in the model handle the capacity restrictions, shortages restrictions. The following constraint ensures that an activated supplier cannot supply more that capacity.

$$
X_{i j t} \leq C P_{i j} V_{i j t} \quad \forall i, j, t
$$

Xit calculates total quantity to be supplied from all active suppliers.

$$
X_{i t}=\sum_{j=1}^{J} X_{i j t} \quad \forall i, t
$$

In a period, for a particular product, only one supplier will be allowed to supply goods is assured by the constraint.

$$
\sum_{j=1}^{J} V_{i j t}=1 \quad \forall i, t
$$

Following three equations calculate inventory in period $t$ at warehouse and ensure no shortage at destination.

$$
\begin{gathered}
I S_{i t}=I S_{i t-1}+X_{i t}-D_{i t} \quad \forall i, t>1 \\
I S_{i t}=I S N_{i t}+X_{i t}-D_{i t} \quad \forall i, t=1 \\
\sum_{t=1}^{T} I S_{i t}+\sum_{t=1}^{T} X_{i j} \geq \sum_{t=1}^{T} D_{i t} \quad \forall i
\end{gathered}
$$

Next equation is an integrator and calculates the total weighted quantity to be transported from warehouse to retail store.

$$
L_{t}=\sum_{i=1}^{P} \omega_{i} X_{i t} \quad \forall t
$$

The constraint mentioned below checks the transportation policy as per the weighted quantity. It clearly specifies that, if the total weighted quantity is above the capacity of truck then LTL policy will get activated and otherwise only TL policy will be used.

$$
L_{t} \leq\left(y_{t}+j_{t} w\right) u_{t}+\left(j_{t}+1\right) w\left(1-u_{t}\right) \quad \forall t
$$

The equation measures the overhead weights from truckload capacity.

$$
L_{t}=y_{t}+j_{t} w \quad \forall t
$$

Next three constraints calculate inventory and optimum demand size at the destination, while considering deterioration percentage and ensuring no shortages.

$$
\begin{gathered}
I D_{i t}=I D N_{i t}+D_{i t}-\tilde{C R_{i t}} \quad \forall i, t=1 \\
I D_{i t}=I D_{i t-1}+D_{i t}-\tilde{C R_{i t}} \quad \forall i, t>1 \\
\sum_{t=1}^{T} I D_{i t}+\sum_{t=1}^{T} D_{i t} \geq \sum_{t=1}^{T} \tilde{C R_{i t}} \quad \forall i
\end{gathered}
$$

Following three equations evaluate carbon emission as per distance travelled and choose the level of cost as per emission threshold.

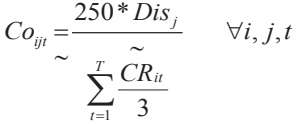

$$
\begin{aligned}
& C O_{i j t} \geq \sum_{l=1}^{L} \text { Amount }_{j t l} P C_{j t l} \quad \forall i, j, t \\
& \sum_{l=1}^{L} P C_{j t l}=1 \quad \forall j, t
\end{aligned}
$$

Following three equations calculate deteriorated inventory, and ensures that warehouse cannot dispose more than its capacity.

$$
\begin{gathered}
E X_{i t}=\eta I D_{i t-1} \quad \forall i, t>1 \\
E X_{i t}=0 \quad \forall i, t=1 \\
\sum_{i=1}^{P} E X_{i t} \leq \sum_{i=1}^{P} D^{P} \text { a }_{i t} \quad \forall t
\end{gathered}
$$

Finally constraint mentioned below enforces the binary and non-negativity restrictions on decision variables.

$X_{i j t}, X_{i t}, L_{t}, D_{i t}, C O_{i j t} \geq 0 ; V_{i j t}, u_{t}, P C_{j t l} \in[0,1] ; I S_{i t}, I D_{i t}, E X_{i t} y_{t}, j_{t}$ are integer

\section{F. Formulated Model}

$$
\begin{aligned}
& \operatorname{Min} \tilde{C}=\sum_{t=1}^{T} \sum_{j=1}^{J} \sum_{i=1}^{P} \phi_{i j t} X_{i j t} V_{i j t}+\sum_{t=1}^{T} \sum_{i=1}^{P} \tilde{H}{ }_{i t} X_{i t} \\
& +\sum_{t=1}^{T}\left[\left(s y_{t}+j_{t} \beta_{t}\right) u_{t}+\left(j_{t}+1\right) \beta_{t}\left(1-u_{t}\right)\right]+\sum_{t=1}^{T} \tilde{H} D_{i t} I D_{i t} \\
& +\sum_{i=1}^{P} \sum_{t=1}^{T} \lambda_{i t} X_{i t}+\sum_{t=1}^{T} \sum_{i=1}^{P} E X_{i t} V h_{i t}+\sum_{t=1}^{T} \sum_{i=1}^{P} E X_{i t} D C_{i t} \\
& \operatorname{Max} \tilde{\operatorname{PR}}=\sum_{t=1}^{T} \sum_{j=1}^{J} \sum_{i=1}^{P}\left(\tilde{D} T_{i j t}+\tilde{A C_{i j t}}\right) V_{i j t} \\
& \text { Min } P C=\sum_{t=1}^{T} \sum_{j=1}^{J} \sum_{i=1}^{P}\left(\tilde{\operatorname{CO}_{i j t}} V_{i j t}\right) \sum_{l=1}^{L} \operatorname{Cost} P_{j t l} P C_{j t l} \\
& \text { Subject to } X_{i j t} \leq C P_{i j} V_{i j t} \quad \forall i, j, t
\end{aligned}
$$




$$
\begin{aligned}
& X_{i t}=\sum_{j=1}^{J} X_{i j t} \quad \forall i, t \\
& \sum_{j=1}^{J} V_{i j t}=1 \quad \forall i, t \\
& I S_{i t}=I S_{i t-1}+X_{i t}-D_{i t} \quad \forall i, t>1 \\
& I S_{i t}=I S N_{i t}+X_{i t}-D_{i t} \quad \forall i, t=1 \\
& \sum_{t=1}^{T} I S_{i t}+\sum_{t=1}^{T} X_{i j} \geq \sum_{t=1}^{T} D_{i t} \quad \forall i \\
& L_{t}=\sum_{i=1}^{P} \omega_{i} X_{i t} \quad \forall t \\
& L_{t} \leq\left(y_{t}+j_{t} w\right) u_{t}+\left(j_{t}+1\right) w\left(1-u_{t}\right) \quad \forall t \\
& L_{t}=y_{t}+j_{t} w \quad \forall t \\
& I D_{i t}=I D_{i t-1}+D_{i t}-\tilde{C R_{i t}} \quad \forall i, t>1 \\
& I D_{i t}=I D N_{i t}+D_{i t}-\tilde{C R_{i t}} \quad \forall i, t=1 \\
& \sum_{t=1}^{T} I D_{i t}+\sum_{t=1}^{T} D_{i t} \geq \sum_{\sim}^{T} \tilde{C} \tilde{C R}_{i t} \quad \forall i \\
& C O_{i j t}=\frac{250 * \mathrm{Dis}_{j}}{\sim} \quad \forall i, j, t \\
& \sum_{t=1}^{T} \frac{C R_{i t}}{3} \\
& C O_{i j t} \geq \sum_{l=1}^{L} \text { Amount }_{j t l} P C_{j t l} \quad \forall i, j, t \\
& \sum_{l=1}^{L} P C_{j t l}=1 \quad \forall j, t \\
& E X_{i t}=\eta I D_{i t-1} \quad \forall i, t>1 \\
& E X_{i t}=0 \quad \forall i, t=1 \\
& \sum_{i=1}^{P} E X_{i t} \leq \sum_{i=1}^{P} D C a p_{i t} \quad \forall t \\
& X_{i j t}, X_{i t}, L_{t}, D_{i t}, C O_{i j t} \geq 0 ; V_{i j t}, u_{t}, P C_{j t l} \in[0,1] \\
& I S_{i t}, I D_{i t}, E X_{i t} y_{t}, j_{t} \text { are integer }
\end{aligned}
$$

\section{FUZZY SOLUTION ALGORITHM}

The following algorithm specifies the sequential steps to solve the fuzzy mathematical programming problems, discussed by [17].

Step1. Compute the crisp equivalent of the fuzzy parameters using a defuzzification function. Here, ranking technique is employed to defuzzify the parameters as $F(A)=\left(a_{l}+2 a_{m}+a_{u}\right) / 4$, where $a_{l}, a_{m}, a_{u}$ are the Triangular Fuzzy Numbers (TFN).

Step2. Since industry is highly volatile and customer demand changes in every short span, a precise estimation of cost and performance aspirations is a major area of discussion. Hence the better way to come out of such situation is to incorporate tolerance and aspiration level with the main objectives. So the model discussed in section $\operatorname{IV}(F)$ can be re-written as follows:

Find $X$

$$
\begin{aligned}
& X \in S ; \quad(1-\eta) \sum_{t=0}^{T} I D_{i t}+\sum_{t=0}^{T} D_{i t} \geq \sum_{\sim t=0}^{T} \overline{C R}_{i t} \quad \forall i \\
& C o_{i j t}=\frac{250 *{ }^{*} i_{j}}{\sim \sum_{t=1}^{T} \frac{\overline{C R}_{i t}}{3}} \quad \forall i, j, t \\
& C(X) \leq C_{0} \\
& P R \geq P R_{0} \\
& X_{i j t}, X_{i t}, L_{t}, D_{i t}, C O_{i j t} \geq 0 ; V_{i j t}, u_{t}, P C_{j t t} \in[0,1] ; I S_{i t}, I D_{i t}, E X_{i t} y_{t}, j_{t} \text { are integer }
\end{aligned}
$$

Step3. Define appropriate membership functions for each fuzzy inequalities as well as constraint corresponding to the objective functions.

$\mu_{C}(X)= \begin{cases}1 & ; \mathrm{C}(X) \leq C_{0} \\ \frac{C_{0}^{*}-C(X)}{C_{0}^{*}-C_{0}} & ; \mathrm{C}_{0} \leq C(X)<C_{0}^{*} ; \mu_{P R}(X)=\left\{\begin{array}{ll}1 & ; P R \geq P R_{0} \\ 0 & ; \mathrm{C}(X)>C_{0}^{*}\end{array} \frac{P R-P R_{0}^{*}}{P R_{0}-P R_{0}^{*}}\right. \\ 0 & ; P R_{0}^{*} \leq P R<P R_{0}\end{cases}$

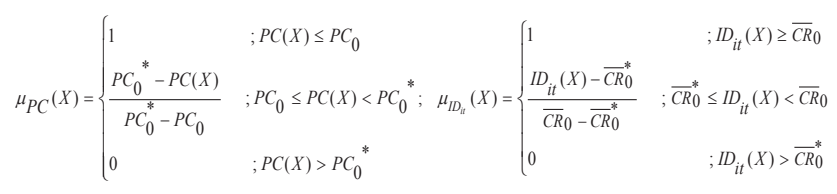

$\mu_{C O_{j i t}}(X)=\left\{\begin{array}{lc}1 & ; \mathrm{CO}_{i j t}(X) \geq \overline{C R}_{0} \\ \frac{C O_{i j t}(X)-\overline{C R}_{0}^{*}}{\overline{C R}_{0}-\overline{C R}_{0}^{*}} & ; \overline{C R}_{0}^{*} \leq C O_{i j t}(X)<\overline{C R}_{0}, \text { where } \overline{C R}_{0}=\sum_{t=1}^{T} \overline{C R}_{i t} \\ 0 & ; \mathrm{CO}_{i j t}(X)>\overline{C R}_{0}^{*}\end{array}\right.$

Step4. Employ extension principles to identify the fuzzy decision, which results in a crisp mathematical programming problem given by Maximize $\boldsymbol{\alpha}$

$$
\begin{gathered}
\text { s.t. } \mu_{c}(X) \geq w_{1} \alpha \\
\mu_{P R}(X) \geq w_{2} \alpha \\
\mu_{P C}(X) \geq w_{3} \alpha \\
\mu_{I D_{i t}}(X) \geq \alpha \\
\mu_{C O_{i j t}}(X) \geq \alpha \\
X \in S
\end{gathered}
$$$$
w_{1} \geq 0, w_{2} \geq 0, w_{3} \geq 0, w_{1}+w_{2}+w_{3}=1, \alpha \in[0,1]
$$

Where, $\alpha$ represents the degree to which the aspiration of the decision-maker is met. The above problem can be solved by the standard mathematical programming algorithms.

Step5. Following [18], while solving the problem by following steps 1-4, the objective of the problem is also treated as a constraint. Each constraint is considered to be an objective for the decision-maker and the problem is looked at as a fuzzy bi objective mathematical programming problem. Further, each objective can have a different level of importance and can be assigned weights to measure relative importance. The resulting problem can be solved by 
the weighted min max approach. On substituting values for $\mu_{P R}(\mathrm{x}), \mu_{P C}(\mathrm{x})$ and $\mu_{C}(\mathrm{x})$ the problem becomes as follows:

$$
\begin{gathered}
\text { Maximize } \boldsymbol{\alpha} \\
\text { s.t } \quad P R(\mathrm{X}) \geq P R_{0}-\left(1-w_{1} \alpha\right)\left(P R_{0}-P R_{0}^{*}\right) \\
C(\mathrm{X}) \leq C_{0}+\left(1-w_{2} \alpha\right)\left(C_{0}^{*}-C_{0}\right) \\
P C(\mathrm{X}) \leq P C_{0}+\left(1-w_{3} \alpha\right)\left(P C_{0}^{*}-P C_{0}\right) \\
\mu_{I D_{i t}}(X) \geq \alpha \\
\mu_{C O_{i j t}}(X) \geq \alpha \\
X \in S \\
w_{1} \geq 0, w_{2} \geq 0, w_{3} \geq 0, w_{1}+w_{2}+w_{3}=1, \alpha \in[0,1]
\end{gathered}
$$

Step6. If a feasible solution is not possible in Step 5, then fuzzy goal programming approach is resorted to obtain a compromised solution given by [19]. The method is discussed in detail in the next section.

\section{A. Fuzzy Goal ProgrammingMethod}

On solving the problem, we found that the problem (P1) is not feasible; hence the management goal cannot be achieved for a feasible value of $\alpha \in[0,1]$. We then apply the fuzzy goal programming technique to obtain a compromised solution. The approach is based on the goal programming technique to solve the crisp goal programming problem given by [14]. The maximum value of any membership function can be 1 ; maximization of $\alpha \in[0,1]$. This can be achieved by minimizing the negative deviational variables of goal programming (i.e., $\eta$ ) from 1. The fuzzy goal programming formulation for the given problem (P1) introducing the negative and positive deviational variables $\eta \mathrm{j}, \rho \mathrm{j}$ is given as

$$
\begin{aligned}
& \text { Minimize } \boldsymbol{u} \\
& \text { s.t. } \quad \mu_{P R}(X)+\eta_{1}-\rho_{1}=1 \\
& \mu_{C}(X)+\eta_{2}-\rho_{2}=1 \\
& \mu_{P C}(X)+\eta_{3}-\rho_{3}=1 \\
& u \geq w_{j} * \eta_{j}, j=1,2,3 \\
& \eta_{j} * \rho_{j}=0, \quad j=1,2,3 \\
& w_{1}+w_{2}+w_{3}=1 \\
& \alpha=1-u ; \eta_{j}, \rho_{j} \geq 0, \mathrm{X} \in \mathrm{S}, u \in[0,1] ; w_{1}, w_{2}, w_{3} \geq 0
\end{aligned}
$$

The above described model is coded into Lingo 11.0 to find the optimal solution.

\section{CASE STUDY}

In the scenario of multi brand stores like super market, big grocery retail stores are flourishing. These big store companies order in huge quantities from their suppliers and distribute the quantity to fulfill consumption of each retail store. The problem arises with these stores are generally, how to make floor plan, managing and optimally using the capacity, replenishment period and capacity to keep inventory. These problems emerge management terminologies and employ their technicalities to manage the issues.
Grocery items and packaged food \& snacks are easily available in these stores but the problem faced in keeping these products is their deteriorating nature, which makes demand of these products uncertain. Same is the problem of company discussed in this paper. Company wants to find out an optimum minimized cost comprising of procurement, transportation, holding, inspection and return channel, choosing suppliers with maximum performance and minimum carbon emission cost with respect to distance travelled from supplier to warehouse point. The problems faced by the company are uncertain consumption, uncertain performance parameters of the suppliers and they also have to adhere the aspiration and tolerance level of carbon emission.

Hence, a model has been developed to find an optimum plan of procurement \& distribution in forward supply chain and cost of transportation in return channel for deteriorated products. The process they follow as, they have multiple suppliers who can supply all types of products. The quantity procured from all suppliers is transported to a warehouse. From the warehouse, quantity is transported to retail stores as per the requirement. To validate the model proposed in this paper, we are showing a problem of multi supplier, one warehouse and one retail store. Four products namely Peanut Chikki (PC) (1000 gms.), Roasted Chana (RC) (500 gms.), Bajra Puff (BP) (1000 gms.), Oat wholemeal Biscuit (OWB) (500 gms.). The data for parameters is discussed as follows:

TABLE I. PURChASE COST PER UNIT (IN INR)

\begin{tabular}{|c|c|c|c|c|c|c|c|c|c|}
\hline & \multicolumn{3}{|c|}{ Supplier 1 } & \multicolumn{3}{c|}{ Supplier 2 } & \multicolumn{3}{c|}{ Supplier 3 } \\
\hline Product & $\boldsymbol{P 1}$ & $\boldsymbol{P 2}$ & $\boldsymbol{P 3}$ & $\boldsymbol{P 1}$ & $\boldsymbol{P 2}$ & $\boldsymbol{P 3}$ & $\boldsymbol{P 1}$ & $\boldsymbol{P 2}$ & $\boldsymbol{P 3}$ \\
\hline PC & 350 & 360 & 365 & 360 & 365 & 365 & 355 & 366 & 369 \\
\hline RC & 200 & 215 & 225 & 200 & 225 & 235 & 220 & 235 & 245 \\
\hline BP & 410 & 415 & 425 & 420 & 435 & 435 & 420 & 425 & 435 \\
\hline OWB & 225 & 235 & 240 & 200 & 215 & 225 & 235 & 245 & 250 \\
\hline
\end{tabular}

Where $\mathrm{P} 1=$ Period $1, \mathrm{P} 2=$ Period $2, \mathrm{P} 3=$ Period 3

TABLE II. HOLDING COST PER UNIT (IN INR)

\begin{tabular}{|c|c|c|c|c|c|c|}
\hline & \multicolumn{3}{|c|}{ WAREHOUSE } & \multicolumn{3}{c|}{ RETAIL STORE } \\
\hline Product & $\boldsymbol{P 1}$ & $\boldsymbol{P 2}$ & $\boldsymbol{P 3}$ & $\boldsymbol{P 1}$ & $\boldsymbol{P} 2$ & $\boldsymbol{P 3}$ \\
\hline PC & 2.5 & 2.8 & 2.3 & 3.2 & 3.1 & 3 \\
\hline RC & 2.3 & 3 & 2.5 & 2.8 & 2.9 & 2.6 \\
\hline BP & 3.4 & 2.7 & 2 & 3.5 & 2.9 & 2.5 \\
\hline OWB & 3.2 & 2.2 & 2.1 & 3.6 & 2.6 & 2.3 \\
\hline
\end{tabular}

TABLE III. INSPECTION, RETURN CHANNEL AND DISPOSAL COST PER UNIT (IN INR)

\begin{tabular}{|c|c|c|c|c|c|c|c|c|c|}
\hline & \multicolumn{3}{|c|}{ Inspection Cost } & \multicolumn{3}{c|}{ Vehicle return Cost } & \multicolumn{3}{c|}{ Disposal Cost } \\
\hline Product & $\boldsymbol{P 1}$ & $\boldsymbol{P} 2$ & $\boldsymbol{P 3}$ & $\boldsymbol{P 1}$ & $\boldsymbol{P} \mathbf{2}$ & $\boldsymbol{P} \mathbf{3}$ & $\boldsymbol{P 1}$ & $\boldsymbol{P 2}$ & $\boldsymbol{P 3}$ \\
\hline PC & 1 & 1 & 1 & 2 & 1.5 & 2 & 3 & 3 & 3 \\
\hline RC & 1.5 & 1.5 & 1.5 & 1.5 & 3 & 1.5 & 3.5 & 3.5 & 3.5 \\
\hline BP & 1 & 1 & 1 & 2 & 2 & 1.5 & 3 & 3 & 3 \\
\hline OWB & 1.5 & 1.5 & 1.5 & 3 & 2 & 2 & 4 & 4 & 4 \\
\hline
\end{tabular}

TABle IV. Performance Percentage

\begin{tabular}{|c|c|c|c|c|c|c|}
\hline & \multicolumn{3}{|c|}{ On-time Delivery } & \multicolumn{3}{c|}{ Lot Acceptance } \\
\hline Product & $\boldsymbol{S} \mathbf{1}$ & $\boldsymbol{S} \mathbf{2}$ & $\boldsymbol{S 3}$ & $\boldsymbol{S 1}$ & $\boldsymbol{S} \mathbf{2}$ & $\boldsymbol{S} \mathbf{3}$ \\
\hline PC & 0.88 & 0.87 & 0.81 & 0.84 & 0.84 & 0.84 \\
\hline $\mathrm{RC}$ & 0.85 & 0.83 & 0.8 & 0.87 & 0.8 & 0.8 \\
\hline BP & 0.95 & 0.9 & 0.95 & 0.9 & 0.81 & 0.94 \\
\hline OWB & 0.81 & 0.93 & 0.81 & 0.9 & 0.92 & 0.82 \\
\hline
\end{tabular}

Where S1=Supplier 1, S2=Supplier 2, S3=Supplier 3 
TABLE V. CARBON EMISSION PENALTy COST PER UNIT (IN INR)

\begin{tabular}{|c|c|c|c|c|c|c|}
\hline & \multicolumn{2}{|c|}{ Period 1 } & \multicolumn{2}{c|}{ Period2 } & \multicolumn{2}{c|}{ Period 3 } \\
\hline Penalty Breaks & Break 1 & Break 2 & Break 1 & Break 2 & Break 1 & Break 2 \\
\hline Supplier 1 & 4 & 8 & 3 & 7 & 5 & 10 \\
\hline Supplier 2 & 4 & 9 & 4 & 8 & 4 & 9 \\
\hline Supplier 3 & 5 & 10 & 4 & 9 & 4 & 8 \\
\hline
\end{tabular}

TABLE VI. CONSUMPTION AT RETAIL STORES (IN UNITS)

\begin{tabular}{|c|c|c|c|}
\hline Product & Period 1 & Period 2 & Period 3 \\
\hline PC & 169 & 138 & 185 \\
\hline RC & 135 & 176 & 182 \\
\hline BP & 167 & 184 & 169 \\
\hline OWB & 174 & 179 & 165 \\
\hline
\end{tabular}

TABLE VII. SUPPLIER's CAPACITY (IN UNITS)

\begin{tabular}{|c|c|c|c|}
\hline Product & Supplier 1 & Supplier 2 & Supplier 3 \\
\hline PC & 250 & 300 & 130 \\
\hline RC & 120 & 220 & 170 \\
\hline BP & 350 & 130 & 340 \\
\hline OWB & 230 & 120 & 240 \\
\hline
\end{tabular}

TABLE VIII. INITIAL INVENTORY (IN UNITS)

\begin{tabular}{|c|c|c|c|c|}
\hline Initial Inventory & PC & RC & BP & OWB \\
\hline Warehouse & 70 & 80 & 40 & 59 \\
\hline Retail store & 90 & 85 & 79 & 83 \\
\hline
\end{tabular}

In table $\mathrm{V}$, first break of penalty cost is applicable for less than $150 \mathrm{gm}$ carbon emission per kilometer, and afterwards second break is applied. The distance between first supplier to warehouse is $30 \mathrm{~km}$, second supplier to warehouse is $20 \mathrm{~km}$ and distance between third supplier to warehouse is $15 \mathrm{~km}$. Transportation from warehouse to retail store costs per truck as per truckload weight of $350 \mathrm{~kg}$. The cost per truck in three periods is Rs.950, Rs.1000 and Rs.1200. Weights which exceed truckload may also be transported per weight base. The cost of transportation per weight is Rs.5. It is observed that the deterioration percentage at retail store is $6 \%$. The deteriorated quantity returns back to warehouse for disposal. The disposal capacity is 100 units for PC, 80 units for RC, 90 units for $\mathrm{BP}$ and 95 units for OWB.

\section{A. Results and Managerial Implication}

The cost incurred to manage procurement and distribution is Rs.4,59,229.7, keeping fuzzy aspiration levels as Rs.3,80,000, Rs.4,00,000, Rs.4,20,000 and defuzzified aspiration cost is Rs.4,00,000 with tolerance of $4,80,000$. The performance of suppliers is quantified as 9.315400 with fuzzy aspiration levels as $11,13, \& 11$. Defuzzified aspiration and tolerance level are 12 and 9 respectively. Measuring carbon emission is not important to reduce the cost but it is our responsibility to improve environment condition for our future generations. The model is able choose the supplier as per minimum distance from supplier to warehouse. The Penalty cost because of carbon emission during travel between supplier and warehouse is Rs.4312.885. Fuzzy aspired costs carbon emission are Rs.3200, Rs.3400 \& Rs. 2000, defuzzified aspired cost is Rs.3000 with tolerance level of Rs. 4500 .
Nearby $73 \%$ of the aspiration level of cost, performance and carbon emission cost has been attained which makes the environment more certain and crisp for future discussions. The model tries to employ high performers to procure ordered quantity and ensure that only the best supplier shall fulfill the demand. Table IX shows the exact quantity procured from suppliers per product per period as per the performance.

TABLE IX. OPTIMUM ORDERED QUANTITY

\begin{tabular}{|c|c|c|c|c|c|c|c|c|c|}
\hline & \multicolumn{3}{|c|}{ Period 1 } & \multicolumn{3}{c|}{ Period 2 } & \multicolumn{3}{c|}{ Period 3 } \\
\hline Product & $\boldsymbol{S 1}$ & $\boldsymbol{S 2}$ & $\boldsymbol{S 3}$ & $\boldsymbol{S 1}$ & $\boldsymbol{S 2}$ & $\boldsymbol{S 3}$ & $\boldsymbol{S 1}$ & $\boldsymbol{S 2}$ & $\boldsymbol{S 3}$ \\
\hline PC & 0 & 292 & 0 & 0 & 40 & 0 & 0 & 0 & 0 \\
\hline RC & 120 & 0 & 0 & 120 & 0 & 0 & 0 & 0 & 88 \\
\hline BP & 0 & 0 & 210 & 0 & 0 & 191 & 0 & 0 & 0 \\
\hline OWB & 0 & 120 & 0 & 0 & 120 & 0 & 0 & 0 & 136 \\
\hline
\end{tabular}

The positive quantity in the table indicates that only the corresponding supplier is activated to supply goods as they have highest performance among the three. Some exceptions also exist, as in period 3 for PC and BP, supplier 3 is activated but no supply takes place.

Table $\mathrm{X}$ shows the ending inventory figures. It is observed that in almost all cases in the last periods, in-hand inventory is consumed and reaches zero or a small positive value.

TABLE $X . \quad$ INVENTORY LEVEL

\begin{tabular}{|c|c|c|c|c|c|c|}
\hline & \multicolumn{3}{|c|}{ Warehouse } & \multicolumn{3}{c|}{ Retail Store } \\
\hline Product & Period 1 & Period 2 & Period 3 & Period 1 & Period 2 & Period 3 \\
\hline PC & 279 & 185 & 0 & 4 & 0 & 0 \\
\hline RC & 128 & 92 & 0 & 22 & 2 & 0 \\
\hline BP & 162 & 130 & 0 & 0 & 39 & 0 \\
\hline OWB & 71 & 29 & 0 & 17 & 0 & 0 \\
\hline
\end{tabular}

The demand from retail store for supplier is shown in Table $\mathrm{XI}$ and depends on consumption at the retail store. The demand provides a basic idea to order.

TABLE XI. DEMAND FROM RETAIL STORE

\begin{tabular}{|c|c|c|c|}
\hline Product & Period 1 & Period 2 & Period 3 \\
\hline PC & 82.69113 & 134.3089 & 185 \\
\hline RC & 72 & 156 & 180 \\
\hline BP & 88.30887 & 222.6911 & 130 \\
\hline OWB & 108 & 162 & 165 \\
\hline
\end{tabular}

While transporting weighted quantity to retail store, policy type, number of trucks and overhead weights are to be checked as each of them incurs cost to the company. In Table XII, it is observed that in period 2 and 3 TL\&LTL policy is employed, as there is a positive overhead quantity. And in first period only TL policy as transporting overhead quantity the cost per unit is higher than full truck cost. In the case of TL\&LTL policy, if overhead weighted quantity is transported through full TL, the cost of transportation will become much higher than using LTL policy. 
TABLE XII. TRANSPORTED WEIGHTS, NO. OF TRUCKS, TRANSPORTATION MODE, OVERHEAD WEIGHT

\begin{tabular}{|c|c|c|c|}
\hline & Period 1 & Period 2 & Period 3 \\
\hline Transported Quantity (in kg) & 622 & 351 & 112 \\
\hline No. Of Trucks & 2 & 1 & 0 \\
\hline Transportation Mode & TL & TL \& LTL & TL \& LTL \\
\hline Overhead Quantity & 0 & 1 & 112 \\
\hline
\end{tabular}

As per the data provided, we receive negligible deteriorated quantity; hence cost of disposal is also near to zero.

Further, optimal carbon emission penalty cost was calculated on the basis of distance which is converted in per unit of each product. Table XIII shows the carbon emission (in gms) along with penalty cost per gram per unit.

TABLE XIII. CARBon EMISSION PENALTy COST

\begin{tabular}{|c|c|c|c|c|c|c|c|c|c|}
\hline & \multicolumn{4}{|c|}{ Period 1 } & \multicolumn{3}{c|}{ Period 2 } & \multicolumn{3}{c|}{ Period 3 } \\
\hline Product & S1 & $\boldsymbol{S 2}$ & $\boldsymbol{S 3}$ & $\boldsymbol{S 1}$ & $\boldsymbol{S 2}$ & $\boldsymbol{S 3}$ & $\boldsymbol{S 1}$ & $\boldsymbol{S 2}$ & $\boldsymbol{S 3}$ \\
\hline PC & 133 & 89 & 67 & 163 & 109 & 82 & 122 & 81 & 61 \\
\hline $\mathrm{RC}$ & 167 & 111 & 83 & 128 & 85 & 64 & 124 & 82 & 62 \\
\hline $\mathrm{BP}$ & 135 & 90 & 67 & 122 & 82 & 61 & 133 & 89 & 67 \\
\hline OWB & 129 & 86 & 65 & 126 & 84 & 63 & 136 & 90 & 68 \\
\hline
\end{tabular}

\section{CONCLUSION}

The supplier selection problem of multiple sourcing includes both selecting suppliers and allocating optimal order quantity among the selected suppliers, based on quality and delivery time criterion. In this study a multi sourcing procurement distribution problem is considered as a multi objective fuzzy optimization programming problem. A typical multi objective supplier selection model which considers three objective functions as minimization of costs, maximization of performance and minimization of carbon emission penalty cost with fuzzy aspiration levels repectively and fuzzy parameters are employed to construct fuzzy mathematical models. Each fuzzy parameter is represented mathematically by using an appropriate membership function. To solve the model, fuzzy goal programming with priority based is applied. The process provides balance among three objective functions and finds best supplier with optimal procurement distribution and penalty cost.

\section{REFERENCE}

[1] H. L. Yi, L. Chinho, and L. Binshan, "On conflict and cooperation in a two-echelon inventory model for deteriorating items," Computers and Industrial Engineering, Vol. 59, pp. 703-711, 2010.

[2] Z.L. Chen and G.L. Vairaktarakis, "Integrated scheduling of production and distribution operations," Management Science, Vol. 51, PP. 614-628, 2005.
[3] Z.L. Chen and G. Pundoor, "Order assignment and scheduling in a supply chain,” Operations Research, Vol. 54, pp. 555-572,2006.

[4] G. Pundoor, and Z.L. Chen, "Joint cyclic production and delivery scheduling in a two stage supply chain," International Journal of Production Economics, Vol. 119, PP. 55-74, 2009.

[5] G. Wang and L. Lei, "Polynomial-time solvable cases of the capacitated multi echelon shipping network scheduling problem with delivery deadlines," International Journal of Production Economics, Vol. 137, pp. 263-271, 2012.

[6] S. Liu, and L.G. Papageorgiou, "Multi objective optimization of production, distribution and capacity planning of global supply chains in the process industry," Omega: The International Journal of Management Science, Vol. 41, pp. 369-382, 2013.

[7] G. Alyanak and O. Armaneri, "An integrated supplier selection and order allocation approach in a battery company," Makine Mühendisleri Odasi, Vol. 19, pp. 2-19, 2009.

[8] F. Jolai, S.A. Yazdian, K. Shahanaghi, and M. AzariKhojasteh, "Integrating fuzzy TOPSIS and multi-period goal programming for purchasing multiple products from multiple suppliers," Journal of Purchasing and Supply Management, 2011, Vol. 17, pp. 42-53, 2011.

[9] O.P. Dubey, R.K. Dwivedi, S.N. Singh, "Goal programming: a survey (1960- 2000)," IUP Journal of Operations Management, Vol. 14, pp.29-53, 2012.

[10] N. Esfandiari and M. Seifbarghy, "Modeling a stochastic multiobjective supplier quota allocation problem with price-dependent ordering," Appl. Math. Modell., Vol. 37, pp.5790-5800, 2013.

[11] A.H.I. Lee, H.-Y. Kang, C.-M. Lai, and W.-Y. Hong, "An integrated model for lot sizing with supplier selection and quantity discounts," Appl. Math. Modell., Vol. 37, pp. 4733-4746, 2013.

[12] A. Amid, S.H. Ghodsypour and C. O'Brien, "Fuzzy multiobjective linear model for supplier selection in a supply chain," Int. J. Prod. Econ., Vol. 104, pp. 394-407, 2006.

[13] M. Bevilacqua, F.E. Ciarapica, and G. Giacchetta, "A fuzzy-QFD approach to supplier selection," J. Purch. Supply Manage., Vol. 12, pp. 14-27, 2006.

[14] T.Y. Wang and Y.H. Yang, "A fuzzy supplier selection in quantity discount environment," Expert System with Applications, Vol. 36, pp. 12179-12187, 2009.

[15] D.D. Wu, Y. Zhang, D. Wu, and D.L. Olson, "Fuzzy multi-objective programming for supplier selection and risk modeling: A possibility approach,” European Journal of Operations Research, Vol. 200, pp. 774-787, 2010.

[16] C.Y. Ku, C.T. Chang, and H.P. Ho, "Global supplier selection using fuzzy analytic Hierarchy process and fuzzy goal programming," Quality and Quantity, Vol. 44, pp. 623-640, 2010.

[17] H.J. Zimmermann, "Description and optimization of fuzzy systems," Int. J. Gen. Syst., Vol. 2, pp. 209-215, 1976.

[18] R.E. Bellman and L.A. Zadeh, "Decision-making in a fuzzy environment,” Manag. Sci., Vol. 17, pp. 141-164, 1970.

[19] R.H. Mohamed, "The relationship between goal programming and fuzzy programming,” Fuzzy Sets Syst., Vol. 89, pp. 215-222, 1997. 